\title{
Many ways of communication: from Helicobacter pylori adherence to death, disruption, migration and escape
}

\author{
Silja Wessler
}

It is almost 30 years ago that Helicobacter pylori (H. pylori) was identified as an important causative agent in the development and progression of a wide range of gastro-intestinal diseases including acute and chronic gastritis, duodenal ulceration, MALT lymphoma and gastric cancer [1,2]. During this time much progress has been made in understanding the complex mechanisms of bacterial pathogenesis which is summarized in this special issue 'Interaction of Helicobacter pylori with its host cell'.

The outcome of gastric disorders is determined by the highly coordinated interaction of bacterial pathogenic factors with signal transduction pathways in host cells leading to diverse cellular responses [3]. Reflecting bacterial pathogenesis as a complex regulated multi-step process $H$. pylori induces disruption of intercellular adhesions, cell motility, apoptosis and the escape from the immune system [4]. The initial step is the bacterial adherence to epithelial host cells. Backert and colleagues [5] describe the molecular interaction of important adherence factors such as BabA/B, SabA, AlpA/B, OipA, and HopZ establishing a tight bacterial contact with host target cells necessary for colonization and pathogenesis of $H$. pylori. While receptors for BabA and SabA have already been identified, the respective binding partners on host cells for OipA, HopZ and AlpA/B are unknown. In this issue, Backert et al. further focus on the selective interaction of cagPAI (cag pathogenicity island) components with integrin $\beta 1$ presented on the surface of gastric epithelial cells [5]. The cagPAI protein CagL decorates the tip of the type IV secretion system and directly binds to $\beta 1$ integrin via an arginine-glycine-aspartate (RGD) motif. This triggers the delivery of the pathogenic factor CagA (cytotoxin associated gene A) into the cytoplasm of host cells as well as activation of $\beta 1$ integrin signaling [6]. Both, integrin $\beta 1$

Correspondence: silja.wessler@sbg.ac.at

Division of Microbiology, Paris-Lodron University, Salzburg, Austria signaling and CagA injection are crucially important in H. pylori pathogenesis as they induce a strong motility and invasive growth of infected epithelial cells $[7,8]$. As summarized in the review of Wessler et al. the well-studied interplay of signal transduction pathways initiated by $\mathrm{CagL} /$ integrin $\beta 1$ binding and CagA is considered as a significant mediator of the dynamic rearrangements in the actin cytoskeleton in $H$. pylori-infected cells in vitro. These factors activate a complex network of signal transduction pathways involving different host cell kinases, adaptor proteins, GTPases, and actin binding proteins and leading to the deregulation of the actin cytoskeleton and actindependent processes such as the formation of lamellipodia, invadopodia and, finally, in combination with proliferative processes, invasive growth [7].

Another important aspect in the step-wise bacterial pathogenesis is the active disruption of lateral cell-to-cell contacts, which perturbs the integrity of the gastric barrier. In this context, tight junctions and adherence junctions are intensively studies and the current knowledge is presented by Wroblewski and Peek in this special issue [9]. Intact intercellular contacts are required to establish and maintain the molecular architecture and selective barrier function of a healthy polarized epithelial tissue. Through the direct interference with components of the junction complexes, $\mathrm{H}$. pylori can actively disturb the barrier function. The bacterial factors VacA, OipA, urease, HtrA, and CagA appear to be involved in the loss of intercellular adhesions which affect tight junctions and adherence junctions extra- or intracellularly as discussed in the review by Wroblewski et al. [9].

Apoptosis is a frequently observed cell response to H. pylori after long-term infections which contribute to the disruption of the barrier function and subsequently to pathogenesis. Apoptosis has been closely related to another important virulence factor, the vacuolating cytotoxin A (VacA), of H. pylori $[10,11]$. Once secreted into the environment of $H$. pylori, it enters the eukaryotic 
host cells exhibiting pleiotropic functions such as vacuolation, suppression of the immune system and the induction of apoptosis. The review by Rassow describes the intracellular traffic route of VacA from the host cell membrane to mitochondria where VacA forms chloride channels, mediates loss of the mitochondrial membrane potential, recruits Bax and Bak, and induces the release of cytochrome c to promote apoptosis [12].

The chronic inflammation in H. pylori-infected individuals significantly enhances the risk of cancer development [13]. Although the immune system is stimulated, persistent infection occurs. This is made possible by the failure of the immune system to clear the H. pylori infection pointing to an immensely successful strategy of immune evasion. The review by Müller and colleagues summarizes the immune cell types and signaling pathways that are involved in establishing persistent infection. Pathogen-associated molecular patterns (PAMPs) and their pattern recognition receptors (PRR), the escape from the $\mathrm{T}$ cell-mediated adaptive immunity and reprogramming of the immune system are discussed. Another aspect considered in this review is the growing recognition of the role of H. pylori in the prevention of allergic and autoimmune diseases in chronically infected individuals [14].

The current knowledge of $H$. pylori pathogenesis is still incomplete, but already points to a strictly regulated multi-step process. This special issue provides a comprehensive overview of presently known $H$. pylori-activated signal transduction pathways leading to different cellular processes and emphasizes the complexity of the communication between $H$. pylori and its host.

Received: 8 September 2011 Accepted: 1 November 2011

Published: 1 November 2011

\section{References}

1. Blaser MJ, Atherton JC: Helicobacter pylori persistence: biology and disease. J Clin Invest 2004, 113:321-333.

2. Peek RM Jr, Crabtree JE: Helicobacter infection and gastric neoplasia. J Pathol 2006, 208:233-248.

3. Wroblewski LE, Peek RM Jr, Wilson KT: Helicobacter pylori and gastric cancer: factors that modulate disease risk. Clin Microbiol Rev 2010, 23:713-739.

4. Wessler S, Backert S: Molecular mechanisms of epithelial-barrier disruption by Helicobacter pylori. Trends Microbiol 2008, 16:397-405.

5. Backert S, Clyne M, Tegtmeyer N: Molecular mechanisms of gastric epithelial cell adhesion and injection of CagA by Helicobacter pylori. Cell Commun Signal 2011.

6. Kwok T, Zabler D, Urman S, Rohde M, Hartig R, Wessler S, Misselwitz R, Berger J, Sewald N, Konig W, Backert S: Helicobacter exploits integrin for type IV secretion and kinase activation. Nature 2007, 449:862-866.

7. Wessler S, Gimona M, Rieder G: Regulation of the actin cytoskeleton in Helicobacter pylori-induced migration and invasive growth of gastric epithelial cells. Cell Commun Signal 2011

8. Schneider S, Weydig C, Wessler S: Targeting focal adhesions: Helicobacter pylori-host communication in cell migration. Cell Commun Signal 2008, $6: 2$

9. Wroblewski LE, Peek RM Jr: Targeted disruption of the epithelial-barrier by Helicobacter pylori. Cell Commun Signal 2011.
10. Galmiche A, Rassow J, Doye A, Cagnol S, Chambard JC, Contamin S, de Thillot V, Just I, Ricci V, Solcia E, Van Obberghen E, Boquet P: The Nterminal $34 \mathrm{kDa}$ fragment of Helicobacter pylori vacuolating cytotoxin targets mitochondria and induces cytochrome c release. EMBO J 2000 19:6361-6370.

11. Kuck D, Kolmerer B, Iking-Konert C, Krammer PH, Stremmel W, Rudi J: Vacuolating cytotoxin of Helicobacter pylori induces apoptosis in the human gastric epithelial cell line AGS. Infect Immun 2001, 69:5080-5087.

12. Rassow J: Helicobacter pylori Vacuolating toxin A and apoptosis. Cell Commun Signal 2011.

13. Correa P: The biological model of gastric carcinogenesis. IARC Sci PubI 2004, 301-310

14. Müller A, Oertli M, Arnold IC: H. pylori exploits and manipulates innate and adaptive immune cell signaling pathways to establish persistent infection. Cell Commun Signal 2011.

doi:10.1186/1478-811X-9-24

Cite this article as: Wessler: Many ways of communication: from Helicobacter pylori adherence to death, disruption, migration and escape. Cell Communication and Signaling 2011 9:24.

\section{Submit your next manuscript to BioMed Central and take full advantage of:}

- Convenient online submission

- Thorough peer review

- No space constraints or color figure charges

- Immediate publication on acceptance

- Inclusion in PubMed, CAS, Scopus and Google Scholar

- Research which is freely available for redistribution 